\title{
Robot-Assisted Minimally Invasive Esophagectomy Reduces the Risk of Recurrent Laryngeal Nerve Palsy
}

\author{
Taro Oshikiri, MD, Hironobu Goto, MD, Manabu Horikawa, MD, Naoki Urakawa, MD, \\ Hiroshi Hasegawa, MD, Shingo Kanaji, MD, Kimihiro Yamashita, MD, Takeru Matsuda, MD, \\ Tetsu Nakamura, MD, and Yoshihiro Kakeji, MD
}

Graduate School of Medicine, Division of Gastrointestinal Surgery, Department of Surgery, Kobe University, Kobe, Japan

\section{PAST}

In esophagectomy for esophageal carcinoma, robot-assisted minimally invasive esophagectomy (RAMIE) is expected to reduce the incidence of recurrent laryngeal nerve (RLN) palsy leading to pneumonia, which is an independent prognostic factor. ${ }^{1,2}$

\section{PRESENT}

Our results showed that RAMIE using the novel "modified Bascule method" can reduce the risk of left RLN palsy during upper mediastinal lymphadenectomy comparing with conventional MIE. ${ }^{3,4}$

\section{FUTURE}

Larger prospective studies are needed to validate the results of this article. In particular, it should be estimated whether RAMIE will improve esophageal carcinoma patients' prognosis by decreasing the risk of RLN palsy.
DISCLOSURES Taro Oshikiri and coauthors have no conflicts of interest or financial ties to disclose.

\section{REFERENCES}

1. Oshikiri T, Takiguchi G, Hasegawa $\mathrm{H}$, et al. Postoperative recurrent laryngeal nerve palsy is associated with pneumonia in minimally invasive esophagectomy for esophageal cancer. Surg Endosc. 2021;35:837-44.

2. Baba Y, Yoshida N, Shigaki H, et al. Prognostic impact of postoperative complications in 502 patients with surgically resected esophageal squamous cell carcinoma: a retrospective single-institution study. Ann Surg. 2016;264:305-11.

3. Oshikiri T, Takiguchi G, Urakawa N, et al. Novel "Modified Bascule method" for lymphadenectomy along the left recurrent laryngeal nerve during robot-assisted minimally invasive esophagectomy. Ann Surg Oncol. 2021. https://doi.org/10.1245/ s10434-021-09738-w.

4. Oshikiri T, Goto H, Manabu Horikawa, et al. Incidence of recurrent laryngeal nerve palsy in robot-assisted versus conventional minimally invasive McKeown esophagectomy in prone position: a propensity score-matched study. Ann Surg Oncol. 2021. https://doi.org/10.1245/s10434-021-10123-w.

Publisher's Note Springer Nature remains neutral with regard to jurisdictional claims in published maps and institutional affiliations.

(C) Society of Surgical Oncology 2021

First Received: 23 April 2021

Accepted: 24 April 2021;

Published Online: 18 May 2021

T. Oshikiri, MD

e-mail: oshikiri@med.kobe-u.ac.jp 